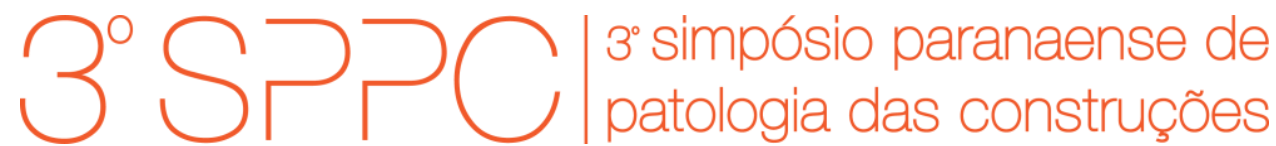

ISSN 2526-7248 artigo n. 3SPPC1016, pp. 174-185, 2018

\title{
Análise do comportamento de aços para estruturas de concreto armado em situação de incêndio
}

\author{
Laske, Ana Claudia ${ }^{1}$; Ibrahim, Boabaid Lucas ${ }^{2}$ \\ 1Bacharel, Universidade Tecnológica Federal do Paraná, laskeac@gmail.com \\ 2Doutor, Universidade Tecnológica Federal do Paraná, lucas.civ@gmail.com
}

Resumo: $O$ concreto é consagrado como um material que apresenta bom desempenho frente a situações de incêndio. Contudo, devido à heterogeneidade entre seus componentes, quando em situações de elevadas temperaturas, ocorrem alterações mecânicas, físicas e químicas que podem comprometer a integridade estrutural dos elementos. Dentre os constituintes deste, o aço é um elemento fundamental, visto que é o responsável pela resistência aos esforços de tração a que os elementos estruturais estão submetidos. Com o objetivo de analisar o comportamento do aço exposto a condição de incêndio, a partir de um procedimento experimental, foram realizados ensaios de tração em corpos de prova de aço CA 50 nas denominações GG 50 e VS 50, submetidos a diferentes temperaturas, sendo estas $200,400,600,800$ e $1000^{\circ} \mathrm{C}$ durante 60 e 120 minutos cada, sendo posteriormente resfriados ao ar livre.

Palavras-chave: Aço, Concreto, Incêndio, Resistência.

Abstract: The concrete is established as a material that shows good performance in fire situations. However, due to the heterogeneity among its componentes in situations of high temperatures, there are mechanical, physical and chemical changes that can compromise the structural integrity of the elements. Among this constituents steel is a fundamental element, because it is responsible for the resistance of traction efforts that the structural elements are subject. With the aim of analyzing the behavior of steel subjected to fire condition from an experimental procedure, were performed traction assays were the samples were subjected to different temperatures, these being $200,400,600,800$ and $1000^{\circ} \mathrm{C}$ during 60 and 120 minutes each, and subsequently cooled in the open air.

Keywords: Steel, Concrete, Fire, Resistance. 
LASKE, A.C.; IBRAHIM, L. B., ANÁLISE DO COMPORTAMENTO DE AÇOS PARA ESTRUTURAS DE CONCRETO ARMADO EM SITUAÇÃO DE INCÊNDIO. $3^{\circ}$ Simpósio Paranaense de Patologia das Construções (3 SPPC), artigo 3SPPC1016, pp. 174 - 185,

\section{Introdução}

As estruturas de concreto apresentam bom desempenho em situação de incêndio, por ser um material incombustível, possuir baixa condutividade térmica, não exalar gases tóxicos quando submetido ao fogo, e os elementos estruturais terem correntemente baixo fator de massividade, as estruturas de concreto são consideradas seguras em situação de incêndio [1].

Vários fatores afetam o desempenho do concreto, assim como de cada um dos seus componentes, como: o tempo de exposição ao fogo, temperatura máxima atingida e tipo de resfriamento.

Com o aumento da temperatura as estruturas apresentam uma acentuada redução de resistência e rigidez, com diminuição da seção resistente, que podem acarretar em danos e plastificações localizados até a ruína parcial ou total da estrutura.

A elevação gradual da temperatura provoca diferentes efeitos nos componentes do concreto, devido à natureza distinta dos seus constituintes. Este passa por diversas modificações, como: diminuição das propriedades mecânicas, físicas e químicas, perda da área resistente e as diferentes respostas ao fogo dadas pela pasta de concreto, os agregados, a água e a armadura.

A análise do comportamento global dos elementos de concreto armado, assim como o de cada um dos seus componentes, é importante para a previsão do seu desempenho. Dentre estes, o comportamento do aço é bastante relevante por conta de suas propriedades térmicas e as consequências do aumento da temperatura na interação com outros constituintes.

Embora o aço seja quimicamente mais estável do que o concreto endurecido, é suscetível aos efeitos da dilatação, da fluência e da redução da resistência e do módulo de elasticidade em função das altas temperaturas. Assim, o estudo do seu comportamento, em razão das alterações que acarreta na resistência e rigidez dos elementos estruturais, é importante.

Por conta do seu amplo uso em diferentes tipos de estruturas, a análise do comportamento do concreto em situações extremas - como o caso de um incêndio -, é importante e necessária. O estudo das estruturas em altas temperaturas visa a diminuição das perdas de vidas humanas e prejuízos econômicos, ambientais e sociais.

\section{Aço em situação de incêndio}

\subsection{Aços para estruturas de concreto armado}

O aço para concreto armado é compreendido como todo aço cujo emprego é adequado para armaduras de concreto armado. $O$ trabalho solidário do concreto com o aço é possível graças à compatibilidade física - visto que o aço e o concreto possuem deformações próximas durante as variações térmicas a temperatura ambiente -, e a compatibilidade química - o aço não se corrói com o ambiente alcalino do concreto -, entre os dois materiais [2]. 
LASKE, A.C.; IBRAHIM, L. B., ANÁLISE DO COMPORTAMENTO DE AÇOS PARA ESTRUTURAS DE CONCRETO ARMADO EM SITUAÇÃO DE INCÊNDIO. $3^{\circ}$ Simpósio Paranaense de Patologia das Construções (30 SPPC), artigo 3SPPC1016, pp. 174 - 185,

Os aços utilizados em estruturas de concreto armado no Brasil são especificados pela norma NBR 7480 [3], que fixa as condições exigíveis na encomenda, fabricação e fornecimento de barras e fios de aço para uso como armaduras para concreto armado.

\subsubsection{Aço em situação de incêndio}

O aço é um material bom condutor de calor, ou seja, a temperatura é uniformizada muito rapidamente na secção das peças. Por este motivo, e dado que as armaduras possuem secções pequenas, é usual considerar-se a temperatura das barras constante em toda a sua seção [4]. Costa e Silva [5], apontam que o aço em relação ao concreto é um melhor condutor térmico. O calor se propaga mais rápido ao longo das barras enquanto o concreto permanece com uma temperatura mais baixa. Desta forma, em situação de incêndio o concreto apresenta-se como importante barreira de proteção das armaduras.

Segundo Ferreira [6], o aço funde à temperatura de $1550^{\circ} \mathrm{C}$, porém os incêndios raramente atingem tal temperatura. Portanto, não há risco das armaduras nas estruturas de concreto armado se fundirem em situação de incêndio. Ainda de acordo com esse autor, as máximas temperaturas alcançadas aproximam-se dos $1200{ }^{\circ} \mathrm{C}$. A NBR 15200 [7] e o EUROCODE 2 [8] assumem que a resistência do aço se anula completamente aos $1200^{\circ} \mathrm{C}$.

Costa e Silva [2] indicam que o tipo de resfriamento a que a estrutura é submetida influencia na aderência do aço: concretos resfriados rapidamente com água sofrem maior perda de aderência que quando resfriados gradualmente ao ar.

\subsubsection{Alterações nas propriedades mecânicas do aço em altas temperaturas}

A alteração da resistência ao escoamento e rigidez do aço da armadura passiva a elevadas temperaturas, deve ser obtida a partir da Tabela 1, conforme a NBR 15200 [7], que preconiza projetos de estruturas de concreto em situação de incêndio.

Tabela 1: Relações $\mathrm{f}_{\mathrm{y}, \theta} / \mathrm{f}_{\mathrm{yk}}$ e $\mathrm{E}_{\mathrm{s}, \theta} / \mathrm{E}_{\mathrm{s}}$ para aços da armadura passiva

\begin{tabular}{cccc}
\hline $\begin{array}{c}\text { Temperatura do aço } \\
\boldsymbol{\theta}\left({ }^{\circ} \mathbf{C}\right)\end{array}$ & \multicolumn{2}{c}{$\mathbf{f}_{\mathbf{y}, \boldsymbol{\theta}} / \mathbf{f}_{\mathbf{y k}}$} & \multirow{2}{*}{$\mathbf{E}_{\mathbf{s}, \boldsymbol{\theta}} / \mathbf{E}_{\mathbf{s}}$} \\
\cline { 2 - 3 } 2 & Tração & Compressão & 5,00 \\
20 & 2,00 & 4,00 & 1,00 \\
100 & 1,00 & 1,00 & 1,00 \\
200 & 1,00 & 1,00 & 0,90 \\
300 & 1,00 & 0,89 & 0,80 \\
400 & 1,00 & 0,78 & 0,70 \\
500 & 1,00 & 0,67 & 0,60 \\
600 & 0,78 & 0,56 & 0,31 \\
700 & 0,47 & 0,33 & 0,13 \\
800 & 0,23 & 0,10 & 0,09 \\
900 & 0,11 & 0,08 & 0,07 \\
1000 & 0,06 & 0,06 & 0,04 \\
1100 & 0,04 & 0,04 & 0,02 \\
1200 & 0,02 & 0,02 & 0,00 \\
\hline
\end{tabular}

A Equação (1) apresenta a relação entre a resistência característica do aço de armadura passiva em situação normal e de incêndio. 
LASKE, A.C.; IBRAHIM, L. B., ANÁLISE DO COMPORTAMENTO DE AÇOS PARA ESTRUTURAS DE CONCRETO ARMADO EM SITUAÇÃO DE INCÊNDIO. $3^{\circ}$ Simpósio Paranaense de Patologia das Construções (30 SPPC), artigo 3SPPC1016, pp. 174 - 185,

$$
f_{y, \theta}=k_{s, \theta} \cdot f_{y k}
$$

Sendo:

$\mathrm{f}_{\mathrm{y}, \theta}$ : resistência característica do aço de armadura passiva na temperatura $\theta$.

$\mathrm{k}_{\mathrm{s}, \theta}$ : fator de redução na temperatura $\theta$.

$\mathrm{f}_{\mathrm{yk}}$ : resistência característica do aço em temperatura ambiente.

A Equação (2) apresenta a relação entre o módulo de elasticidade do aço de armadura passiva em situação normal e de incêndio.

$$
\mathrm{E}_{\mathrm{s}, \theta}=\mathrm{k}_{\mathrm{sE}, \theta} \cdot \mathrm{E}_{\mathrm{s}}
$$

Onde:

$\mathrm{E}_{\mathrm{s}, \theta}$ : módulo de elasticidade do aço da armadura passiva na temperatura $\theta$.

$\mathrm{k}_{\mathrm{sE}, \theta}$ : fator de redução do módulo de elasticidade do aço na temperatura $\theta$.

$\mathrm{E}_{\mathrm{s}, \mathrm{\theta}}$ : módulo de elasticidade do aço em temperatura ambiente.

As Equações (1) e (2) devem ser utilizadas para determinação das propriedades resistentes quando em situação de incêndio.

\section{Materiais e métodos}

Foi quantificada e avaliada a variação das propriedades resistentes de dois tipos de aço CA 50, submetidos a altas temperaturas e resfriados ao ar livre, através de uma abordagem experimental.

\subsection{Materiais analisados}

Os materiais objetos desta pesquisa consistiram em barras de aço CA 50 nas denominações GG 50 e VS 50. Na Figura 1 tem-se as amostras analisadas.

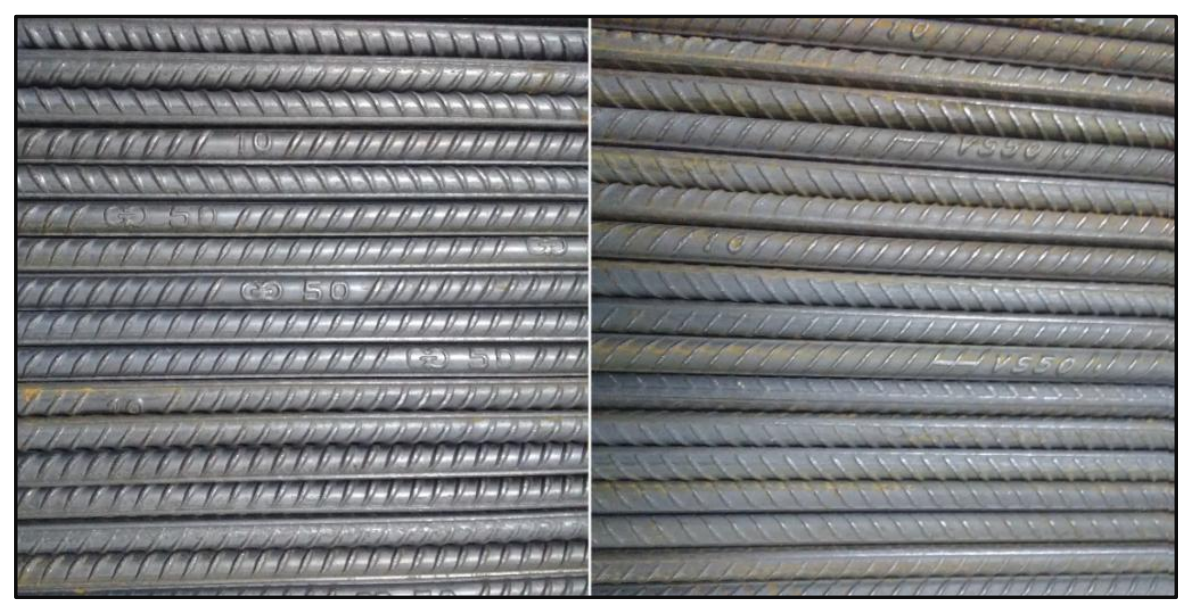

Figura 1: Detalhe das marcas de aço analisadas

Os vergalhões GG 50 são fabricados pela Gerdau, uma empresa siderúrgica brasileira. Segundo a GERDAU [9] o vergalhão Gerdau GG 50 é fornecido na categoria CA-50 com superfície nervurada, produzido rigorosamente de acordo com as especificações da norma NBR 7480 [2]. 
LASKE, A.C.; IBRAHIM, L. B., ANÁLISE DO COMPORTAMENTO DE AÇOS PARA ESTRUTURAS DE CONCRETO ARMADO EM SITUAÇÃO DE INCÊNDIO. $3^{\circ}$ Simpósio Paranaense de Patologia das Construções (30 SPPC), artigo 3SPPC1016, pp. 174 - 185, 2018. DOI: $10.4322 / 2526-7248.016$

Os aços da série VS são fabricados pela Votorantim Siderurgia, empresa criada em 2008, que integra o grupo Votorantim. A VOTORAÇO [10] aponta que a marca foi a primeira no Brasil a obter o certificado da marca de conformidade ABNT para a norma ABNT NBR 7480, homologada pelo INMETRO.

\subsection{Simulação da condição de incêndio e resistência do aço submetido a altas temperaturas}

A amostra foi dividida em 5 grupos de 24 corpos de prova cada que foram aquecidos em diferentes faixas de temperatura e com diferentes tempos de exposição ao calor e 12 barras que foram submetidas ao ensaio de tração sem exposição ao fogo, para servir de parâmetro inicial de resistência, totalizando 132 corpos de prova, conforme exposto na Tabela 2.

Tabela 2: Características das amostras ensaiadas

\begin{tabular}{|c|c|c|c|c|c|c|}
\hline \multirow[t]{2}{*}{$\begin{array}{l}\text { Temperatura } \\
\text { (으) }\end{array}$} & \multirow[t]{2}{*}{$\begin{array}{l}\text { Exposição } \\
\text { calor (min) }\end{array}$} & \multicolumn{2}{|c|}{$\begin{array}{c}\text { Número de } \\
\text { corpos de prova }\end{array}$} & \multirow[t]{2}{*}{$\begin{array}{c}\text { Total de } \\
\text { corpos } \\
\text { de prova }\end{array}$} & \multirow[t]{2}{*}{$\begin{array}{l}\text { Diâmetro } \\
(\mathrm{mm})\end{array}$} & \multirow[t]{2}{*}{$\begin{array}{l}\text { Tipo de } \\
\text { resfriamento }\end{array}$} \\
\hline & & GG 50 & VS 50 & & & \\
\hline 20 & 0 & 6 & 6 & 12 & 10 & Não foi aquecido \\
\hline \multirow{2}{*}{200} & 60 & 6 & 6 & 24 & 10 & \\
\hline & 120 & 6 & 6 & & 10 & Ar livre \\
\hline \multirow{2}{*}{400} & 60 & 6 & 6 & 24 & 10 & Ar livre \\
\hline & 120 & 6 & 6 & & & \\
\hline 600 & $\begin{array}{c}60 \\
120\end{array}$ & 6 & 6 & 24 & 10 & Ar livre \\
\hline \multirow{2}{*}{800} & 60 & $\begin{array}{l}0 \\
6\end{array}$ & $\begin{array}{l}6 \\
6\end{array}$ & & & \\
\hline & 120 & 6 & 6 & 24 & 10 & Ar livre \\
\hline \multirow{2}{*}{1000} & 60 & 6 & 6 & & & \\
\hline & 120 & 6 & 6 & 24 & 10 & Ar livre \\
\hline
\end{tabular}

Para simulação das condições de incêndio foi utilizado um forno Mufla da marca MARQLABOR modelo MAQMUF2RP. Aguardava-se até a estufa atingir a temperatura definida para o ensaio e então os corpos de prova eram colocados nesta. Após o tempo de aquecimento estipulado retirava-se a amostras e mantidas ao ar livre, sendo posteriormente submetidos ao ensaio de tração, conforme Figura 2.

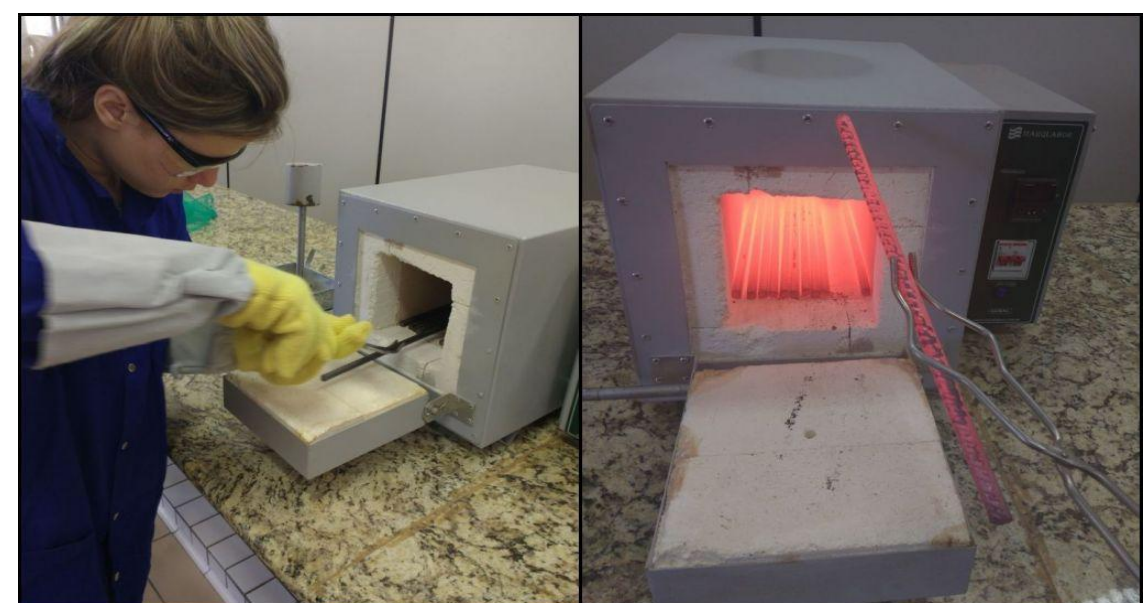

Figura 2: Colocação (esquerda) e retirada (direita) dos corpos de prova do forno 
LASKE, A.C.; IBRAHIM, L. B., ANÁLISE DO COMPORTAMENTO DE AÇOS PARA ESTRUTURAS DE CONCRETO ARMADO EM SITUAÇÃO DE INCÊNDIO. $3^{\circ}$ Simpósio Paranaense de Patologia das Construções (30 SPPC), artigo 3SPPC1016, pp. 174 - 185,

\section{Resistência do aço submetido à situação de incêndio}

$\mathrm{Na}$ Tabela 3 estão relacionados os valores das resistências ao escoamento e última e modulo de elasticidade para o aço GG 50 .

Tabela 3: Propriedades resistentes apresentadas pelo aço GG 50

\begin{tabular}{|c|c|c|c|c|}
\hline $\begin{array}{c}\text { Temperatura } \\
\left({ }^{\circ} \mathrm{C}\right)\end{array}$ & $\begin{array}{c}\text { Tempo de } \\
\text { aquecimento (min) }\end{array}$ & $\mathbf{f}_{\mathrm{y}}(\mathrm{MPa})$ & $\mathbf{f}_{\mathbf{u}}(\mathbf{M P a})$ & $E_{s}(G P a)$ \\
\hline 20 & 0 & 546,6 & 649,6 & 200,51 \\
\hline \multirow{2}{*}{200} & 60 & 542,6 & 646,5 & 197,66 \\
\hline & 120 & 542,1 & 646,2 & 197,42 \\
\hline \multirow{2}{*}{400} & 60 & 542,1 & 645,9 & 187,02 \\
\hline & 120 & 552,7 & 649,1 & 172,34 \\
\hline \multirow{2}{*}{600} & 60 & 508,1 & 589,1 & 159,63 \\
\hline & 120 & 500,8 & 582,9 & 153,87 \\
\hline \multirow[b]{2}{*}{800} & 60 & 317,7 & 476,1 & 127,68 \\
\hline & 120 & 303,5 & 473,7 & 113,72 \\
\hline 1000 & 60 & 258,7 & 428,3 & 108,94 \\
\hline \multicolumn{2}{|c|}{ Desvio padrão } & 121,1 & 86,9 & 35,2 \\
\hline
\end{tabular}

$\mathrm{Na}$ Tabela 4 estão relacionadas as propriedades resistentes apresentadas pelo aço VS 50 .

Tabela 4: Propriedades resistentes apresentadas pelo aço VS 50

\begin{tabular}{ccccc}
\hline $\begin{array}{c}\text { Temperatura } \\
\left({ }^{\circ} \mathbf{C}\right)\end{array}$ & $\begin{array}{c}\text { Tempo de } \\
\text { aquecimento }(\mathbf{m i n})\end{array}$ & $\mathbf{f}_{\mathbf{y}}(\mathbf{M P a})$ & $\mathbf{f}_{\mathbf{u}}(\mathbf{M P a})$ & $\mathbf{E}_{\mathbf{s}}(\mathbf{G P a})$ \\
\hline 20 & 0 & 519,1 & 631,9 & 198,57 \\
200 & 60 & 519,4 & 632,7 & 196,89 \\
& 120 & 517,0 & 630,6 & 186,03 \\
400 & 60 & 527,1 & 633,9 & 183,07 \\
& 120 & 523,2 & 636,7 & 172,34 \\
600 & 60 & 495,4 & 595,7 & 171,75 \\
& 120 & 483,0 & 575,6 & 161,78 \\
800 & 60 & 346,7 & 526,6 & 126,32 \\
1000 & 120 & 333,9 & 518,5 & 107,35 \\
\hline \multicolumn{5}{c}{} \\
\hline
\end{tabular}

Conforme observa-se nas Tabelas 3 e 4 não se obteve resultados das características analisadas para o aquecimento a $1000^{\circ} \mathrm{C}$ por 120 minutos. Isso deve-se porque os corpos de provas apresentaram perda das nervuras a partir da temperatura de $600^{\circ} \mathrm{C}$. Ainda assim, foi possível fixar as barras aquecidas a $800^{\circ} \mathrm{C}$ a 60 e 120 minutos e $1000^{\circ} \mathrm{C}$ durante 60 minutos. Em virtude da descamação das barras de aço, fenômeno que teve início nos materiais aquecidos a $600^{\circ} \mathrm{C}$, não foi possível a realização do ensaio com a utilização do extensômetro, instrumento este que forneceria o módulo de elasticidade das amostras.

Foi necessário obter o módulo de elasticidade a partir de cálculo manual. Para tanto, foram exportados os dados gerados pela máquina de ensaios universal, que relacionava a deformação sofrida pelo corpo de prova e a força aplicada neste. Para cada ensaio, eram apresentados valores de força e deformação a cada 0,01 segundos de aplicação da tensão axial, aproximadamente. 
LASKE, A.C.; IBRAHIM, L. B., ANÁLISE DO COMPORTAMENTO DE AÇOS PARA ESTRUTURAS DE CONCRETO ARMADO EM SITUAÇÃO DE INCÊNDIO. $3^{\circ}$ Simpósio Paranaense de Patologia das Construções (30 SPPC), artigo 3SPPC1016, pp. 174 - 185,

\subsection{Variação da resistência ao escoamento do aço}

Conforme observa-se nas tabelas 3 e 4 , até o aquecimento de $600^{\circ} \mathrm{C}$ as variações de resistência apresentadas não foram significativas para as duas amostras.

Para o aço GG 50 no aquecimento a $800^{\circ} \mathrm{C}$ a resistência apresentada pelo aço foi aproximadamente a metade da amostra de referência: $58,1 \%$ da resistência ao escoamento inicial para 60 minutos e $55,5 \%$ para 120 minutos de aquecimento. No aquecimento a $1000^{\circ} \mathrm{C}$ os corpos de prova tiveram uma redução de $52,7 \%$ no aquecimento durante 60 minutos

Para o VS 50 As amostras aquecidas a $800^{\circ} \mathrm{C}$ exibiram $66,8 \%$ e $64,3 \%$ da resistência inicial. Por último, as amostras submetidas a $1000^{\circ} \mathrm{C}$ por 60 minutos tiveram redução de $40,80 \%$.

Observou-se, para ambas as amostras, que nos dois períodos de aquecimento para as temperaturas de 200,400 e $600^{\circ} \mathrm{C}$ a variação da resistência apresentada pelos corpos de prova foram pequenas. A respeito desse comportamento, Silva et al., [11] apresenta:

[...] Desde que a temperatura do aço não exceda, por certo tempo, a temperatura de transformação de $723^{\circ} \mathrm{C}$, é esperado que o aço permaneça com propriedades metalúrgicas aceitáveis. Após 0 resfriamento à temperatura ambiente, suas propriedades mecânicas residuais serão as mesmas encontradas na condição pré incêndio [11].

A partir do aquecimento a $800^{\circ} \mathrm{C}$ ocorreram significativas alterações na resistência das amostras, por conta das modificações na sua composição química original. Nesta temperatura, o aço sofreu mudanças nas suas propriedades estruturais, conservando-as mesmo após ser resfriado.

\footnotetext{
Qualquer ascensão de temperatura entre $720^{\circ} \mathrm{C}$ e $870^{\circ} \mathrm{C}$ tem um pequeno impacto sobre as propriedades estruturais do aço, após seu resfriamento à temperatura ambiente. Qualquer aquecimento além desses valores causará uma transformação permanente relativa à sua composição química original, que resultará em um crescimento de grão e, algumas vezes, endurecimento, que, com o posterior esfriamento, afetará, de modo adverso, as propriedades mecânicas residuais [11] apud [12].
}

Malhotra [13] apresenta que a resistência do aço é progressivamente reduzida e este amolece em torno dos $800^{\circ} \mathrm{C}$. Tal comportamento pode ser observado no procedimento experimental.

\subsection{Variação da resistência última do aço}

As maiores variações ocorreram a partir de $600^{\circ} \mathrm{C}$. Para o aço GG 50 , o aquecimento a $800^{\circ} \mathrm{C}$ a resistência última apresentada pelo aço foi de $83,34 \%$ da resistência inicial para 60 minutos e $82,05 \%$ para 120 minutos de aquecimento. Para $1000^{\circ} \mathrm{C}$ houve uma diminuição de $34,1 \%$.

Para o VS 50 aos corpos de prova expostos a temperatura de $800^{\circ} \mathrm{C}$ tiveram redução de 16,7\% para 60 minutos e de $17,9 \%$ da resistência última para 120 minutos de aquecimento. As amostras que foram ensaiadas a $1000^{\circ} \mathrm{C}$ apresentou $77,5 \%$ da sua resistência última inicial. 
LASKE, A.C.; IBRAHIM, L. B., ANÁLISE DO COMPORTAMENTO DE AÇOS PARA ESTRUTURAS DE CONCRETO ARMADO EM SITUAÇÃO DE INCÊNDIO. $3^{\circ}$ Simpósio Paranaense de Patologia das Construções (30 SPPC), artigo 3SPPC1016, pp. 174 - 185,

Conforme exposto no item 4.1, os corpos de prova que foram expostos a temperaturas superiores a temperatura crítica do aço apresentaram as maiores reduções de resistência. No entanto, o percentual de redução da resistência última foi inferior a da resistência característica.

Como pode-se perceber a resistência ao escoamento teve um percentual de redução superior a resistência última. O mesmo comportamento observado na resistência característica foi evidenciado pela resistência última: a partir do aquecimento a $600^{\circ} \mathrm{C}$ as propriedades resistentes da amostra começaram a decrescer. Ou seja: as propriedades mecânicas do aço decrescem com as temperaturas, principalmente a tensão de escoamento [14].

\subsection{Variação do módulo de elasticidade do aço}

A partir do aquecimento a $600^{\circ} \mathrm{C}$ começou a haver uma redução no módulo de elasticidade significativa para ambos os materiais. O aço GG 50 aquecimento a $800^{\circ} \mathrm{C}$ o módulo apresentado foi de 36,3\% e 43,3\% da amostra de referência resistência inicial para 60 minutos e 120 minutos de aquecimento, respectivamente. No aquecimento a $1000^{\circ} \mathrm{C}$ os corpos de prova apresentaram valores de módulo de elasticidade correspondentes a aproximadamente metade da amostra de referência: teve-se uma redução de $45,7 \%$ no módulo para aquecimento durante 60 minutos.

A partir do aquecimento a $800^{\circ} \mathrm{C}$ para o VS 50 , as barras começaram a apresentar maiores variações no módulo de elasticidade: para 60 minutos houve redução de $36,4 \%$ e para 120 minutos $45,9 \%$.

Por fim, a $1000^{\circ} \mathrm{C}$ os corpos de prova de aço VS 50 apresentaram valores de módulo de elasticidade correspondentes a aproximadamente metade da amostra de referência: teve-se uma redução de $47,5 \%$ no módulo para aquecimento durante 60 minutos

\subsection{Comparação dos valores das propriedades resistentes obtidos com os apresentados pela NBR 15200 [6].}

Petrucci [15] expõe que as armaduras de aço laminados do concreto recuperam a resistência em incêndios, desde que aquecidos até $500^{\circ} \mathrm{C}$. Conforme pode-se observar nas Tabelas 3 e 4 , até a temperatura de $500^{\circ} \mathrm{C}$ a relações $\mathrm{f}_{\mathrm{y}, \theta} / \mathrm{f}_{\mathrm{yk}}$ e $\mathrm{E}_{\mathrm{s}, \theta} / \mathrm{E}_{\mathrm{s}}$ foram muito próximas - inclusive superiores, a 1.

Wang e Lui [16] apontam ainda, que a perda das propriedades mecânicas pós incêndio dos aços para estruturas de concreto armado são insignificantes para temperaturas abaixo de $600^{\circ} \mathrm{C}$.

Com base nas Tabelas 3 e 4 observa-se que a partir do aquecimento a $800^{\circ} \mathrm{C}$, as barras de aço apresentaram diminuições significativas das propriedades resistentes. Segundo Landi [17] e Petrucci [15], apenas em temperaturas muito elevadas e por longo tempo a granulação poderá se tornar grosseira, impedindo a recuperação total das características originais. 
LASKE, A.C.; IBRAHIM, L. B., ANÁLISE DO COMPORTAMENTO DE AÇOS PARA ESTRUTURAS DE CONCRETO ARMADO EM SITUAÇÃO DE INCÊNDIO. $3^{\circ}$ Simpósio Paranaense de Patologia das Construções (3 SPPC), artigo 3SPPC1016, pp. $174-185$,

$\mathrm{Na}$ Figura 3 tem-se os fatores de redução da resistência do aço obtidos em comparação com o apresentado pela NBR 15200 [6] para armaduras de aço CA 50 tracionada.

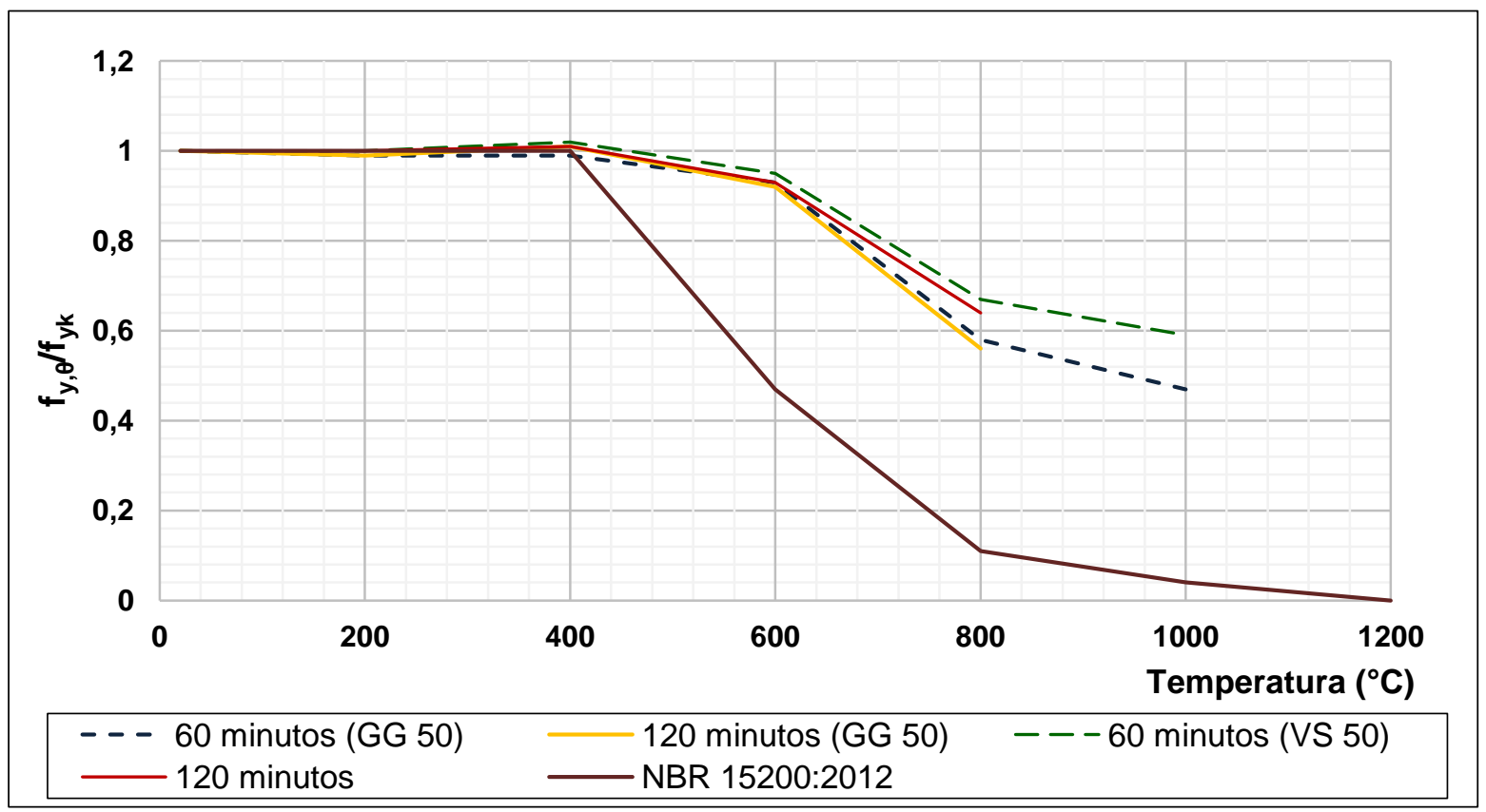

Figura 3: Fator de redução da resistência ao escoamento do aço

Nota-se que o fator de redução da resistência ao escoamento do aço em função da temperatura, ou seja, com as amostras submetidas as condições de incêndio e resfriadas ao ar livre foi consideravelmente inferior ao apresentado pela NBR 15200 [6].

Até $400^{\circ} \mathrm{C}$ os fatores obtidos e o apresentado pela NBR 15200 [6], não tiveram diferenças significativas. Conforme observa-se na tabela 1 , até $400^{\circ} \mathrm{C}$ a norma considera que não há diminuição de resistência durante o incêndio. Somente a partir de $400^{\circ} \mathrm{C}$ que é assumido que há um declínio na resistência do aço.

A partir de $600^{\circ} \mathrm{C}$ as amostras passaram a apresentar diminuição na resistência. No entanto, tal diminuição foi muito inferior a apresentada pela norma. Neste temperatura, os valores do fator $\mathrm{k}_{\mathrm{s}}$ variaram entre 0,92 e 0,95 , enquanto 0 apresentado pela norma é de 0,47. Ou seja, a resistência residual do aço, aquecido na temperatura de $600^{\circ} \mathrm{C}$ é aproximadamente o dobro da apresentada pelo material na mesma temperatura, no momento do incêndio.

Observou-se que o aço tem uma grande capacidade de retomar sua resistência: a NBR 15200 [6], conforme exposto na Tabela 1, apresenta que o aço na temperatura $1000^{\circ} \mathrm{C}$ preserva apenas $4 \%$ de sua resistência ao escoamento e módulo de elasticidade iniciais. $O$ aço aquecido a tal temperatura e resfriado ao ar livre recupera praticamente metade de sua resistência ao escoamento e modulo de elasticidade iniciais, propriedades estas que foram quases anuladas, no momento em que este estava exposto a alta temperatura. 
LASKE, A.C.; IBRAHIM, L. B., ANÁLISE DO COMPORTAMENTO DE AÇOS PARA ESTRUTURAS DE CONCRETO ARMADO EM SITUAÇÃO DE INCÊNDIO. $3^{\circ}$ Simpósio Paranaense de Patologia das Construções (30 SPPC), artigo 3SPPC1016, pp. 174 - 185,

$\mathrm{Na}$ Figura 4 tem-se a comparação entre os valores obtidos para o modulo de elasticidade a partir do procedimento experimental realizado e os apresentados pela NBR 15200 [6].

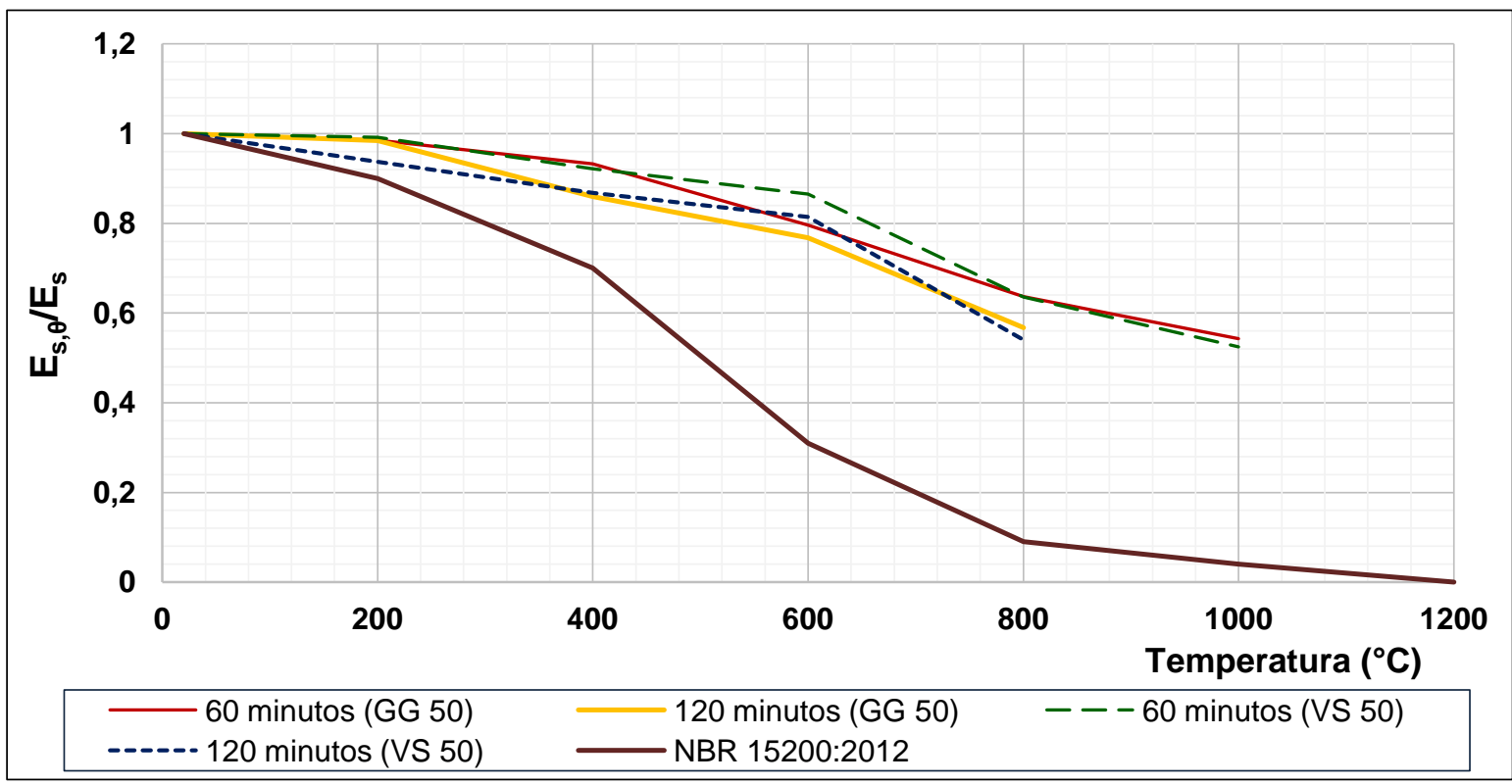

Figura 4: Fator de redução do módulo de elasticidade do aço

Notou-se que os fatores no momento do incêndio, ou seja, a redução de resistência apresentada pelas armaduras quando estão expostas ao fogo são muito superiores ao aço quando resfriado. Bolina [18] apresenta que a redução de resistência estimada se refere àquela verificada no ato do aquecimento.

Observa-se que a recuperação da resistência do aço é muito significativa, visto que, quando este está aquecido tem uma notável diminuição de suas propriedades resistentes. Os aços laminados a quente recuperam as propriedades de resistência quando aquecidos até $1100^{\circ} \mathrm{C}$ ou $1200^{\circ} \mathrm{C}$ e arrefecidos em seguida [19].

\subsection{Comparação entre os materiais analisados}

Notou-se que em situação normal e aquecimento até $600^{\circ} \mathrm{C}$ os materiais apresentaram um desempenho bastante semelhante. A partir desta temperatura, em que as mudanças foram significativas, ou seja, em que o comportamento mecânico das barras foi testado, o aço VS 50 teve desempenho superior.

De maneira geral, observou-se que o aço VS 50 apresentou melhor comportamento frente ao GG 50, por conta de suas propriedades resistentes residuais analisadas terem menores variações com relação aos valores sem exposição ao fogo.

\subsection{Conclusões}

Verificou-se que houve variações significativas nas propriedades resistentes a partir do aquecimento a $800^{\circ} \mathrm{C}$. Notou-se diferenças consideráveis entre os fatores de redução de resistência apresentado pela NBR 15200 [6], no momento do incêndio com os obtidos. 
LASKE, A.C.; IBRAHIM, L. B., ANÁLISE DO COMPORTAMENTO DE AÇOS PARA ESTRUTURAS DE CONCRETO ARMADO EM SITUAÇÃO DE INCÊNDIO. $3^{\circ}$ Simpósio Paranaense de Patologia das Construções (30 SPPC), artigo 3SPPC1016, pp. 174 - 185, 2018. DOI: $10.4322 / 2526-7248.016$

Os resultados obtidos evidenciam redução das resistências ao escoamento e última e módulo de elasticidade quando o aço fica exposto a altas temperaturas.

Segundo a literatura, após o resfriamento, o aço tende a recuperar grande parte de sua resistência. Foi possível realizar tal constatação a partir do procedimento experimental realizado nesse trabalho.

Dentre os materiais analisados, o aço VS 50 apresentou desempenho superior ao GG 50, a partir do aquecimento a $800^{\circ} \mathrm{C}$, em que as propriedades resistentes do aço sofreram diminuições significativas.

Os resultados obtidos com os ensaios ressaltam a necessidade de se aprimorar os estudos sobre o comportamento do aço em altas temperaturas e suas propriedades resistentes residuais, visto que há muitas questões a serem respondidas.

Como sugestão para futuros trabalhos, a autora sugere a avaliação de corpos de prova submetidos as mesmas condições de ensaio desenvolvidas neste trabalho, porém resfriados com água, para o comparativo de desempenho.

\section{Agradecimentos}

Agradeço ao professor Dr. Lucas Boabaid Ibrahim pela sua dedicação e orientação deste trabalho, aos professores da banca examinadora pela atenção e contribuição feitas ao estudo e aos técnicos Wilson e Marcos dos laboratórios de Engenharia Civil pela compreensão com as minhas necessidades e pela ajuda de diferentes maneiras.

\section{Referências}

[1] COSTA, Carla Neves; SILVA, Valdir Pignatta. Estruturas de concreto em situação de incêndio. In: Jornadas Sul-Americanas de Engenharia Estrutural. Brasília, Distrito Federal. 2002. 20 p.

[2] PINHEIRO, Libânio M. Fundamentos de concreto e projeto de edifícios. Universidade de São Paulo. Departamento de Engenharia de estruturas. Sâo Carlos. 2007. 380 p.

[3] ASSOCIAÇÃO BRASILEIRA DE NORMAS TÉCNICAS. Barras e fios de aço destinados a armaduras para concreto armado. NBR 7480. Rio de Janeiro. 2007.

[4] FERNANDES, Márcio Claudio Viveiros. Verificação da resistência ao fogo de estruturas de Betão com bases nos métodos simplificados do EC2 - Parte 1-2. Tese de mestrado em Engenharia Civil (Especialização em Estruturas). Faculdade de Engenharia. Universidade do Porto. Porto, Portugal. 2008.

[5] COSTA, Carla Neves; SILVA, Valdir Pignatta. Estruturas de concreto em situação de incêndio. In: Jornadas Sul-Americanas de Engenharia Estrutural. Brasília, Distrito Federal. 2002. 20 p.

[6] FERREIRA, Sérgio Gonçalves. Ação do incêndio nas estruturas de aço conseqüências e recuperação. In: Simpósio Nacional de Arquitetura e Proteção Contra Incêndios. Anais... EPUSP. São Paulo, 1998.

[7] ASSOCIAÇÃO BRASILEIRA DE NORMAS TÉCNICAS. Projeto de estruturas de concreto em situação de incêndio. NBR 15200. Rio de Janeiro. 2012. 
LASKE, A.C.; IBRAHIM, L. B., ANÁLISE DO COMPORTAMENTO DE AÇOS PARA ESTRUTURAS DE CONCRETO ARMADO EM SITUAÇÃO DE INCÊNDIO. $3^{\circ}$ Simpósio Paranaense de Patologia das Construções (3 SPPC), artigo 3SPPC1016, pp. 174 - 185, 2018. DOI: $10.4322 / 2526-7248.016$

[8] EUROPEAN COMMITTEE FOR STANDARDIZATION. Eurocode 2: design of concrete structures - part 1.2: general rules - structural fire design. EN 1992-1-2. Brussels: CEN, 2004. $97 \mathrm{p}$.

[9] GERDAU. Vergalhão Gerdau GG 50. Disponível em: https://www.gerdau.com/br/pt/ produtos/vergalhao-gerdau-gg-50. Acesso em 10 de março de 2018.

[10] VOTORAÇO. Catálogo de produtos Votoraço VS-50. São Paulo, 2016. 23 p.

[11] SILVA, Valdir Pignatta e; RODRIGUES, Francisco Carlos; FAKURY, Ricardo Hallal; PANNONI, Fabio Domingos. Incêndio real em um apartamento de interesse social: um estudo de caso. Rem: Rev. Esc. Minas [online]. 2007, vol.60, n.2.

[12] KIRBY, B.R., LAPWOOD, D.G. and THOMSON, G. The Reinstatement of Fire Damaged Steel and Iron Framed Structures. British Steel Corporation, Swinden Laboratories. United Kingdom. 1986.

[13] MALHOTRA, Harbans Lal. Properties of Materials at High Temperatures. Technical committee 44-PHT. Materials and Structures. Vol. 15. N86. RILEM. Paris, 1982.

[14] QIANG, X; BIJLAARD, F. S; KOLSTEIN, H. Elevated temperatura mechanical properties of high strength structural steel S460N. Experimental study and recommendations for fire-resistance design. Fire Safety Journal, v. 55. p. 15-21. 2013.

[15] PETRUCCI, Eladio Gerardo Requião. Materiais de Construção. 3ª ed. Editora Globo. Porto Alegre, 1978.

[16] WANG F; LUI E. M. Behavior of High Strength Steels under and After High Temperature Exposure: A Review. Journal of steel structures \& construction. Vol 2. 10 p. 2016.

[17] LANDI, Francisco Romeu. Projeto de Edifícios e Comportamento dos Materiais com relação a Incêndio. Trabalhos de Pós-graduação e Notas de Aula. EPUSP. Departamento de Engenharia Civil. São Paulo. 1977.

[18] BOLINA, Fabrício Longhi. Avaliação experimental da influência dos requisitos de durabilidade na segurança contra incêndio de protótipos de pilares pré- fabricados de concreto armado. Dissertação de Mestrado. PPGAU/UNISINOS, São Leopoldo, RS, Brasil, 2016.

[19] FERNANDES, Márcio Claudio Viveiros. Verificação da resistência ao fogo de estruturas de Betão com bases nos métodos simplificados do EC2 - Parte 1-2. Tese de mestrado em Engenharia Civil (Especialização em Estruturas). Faculdade de Engenharia. Universidade do Porto. Porto, Portugal. 2008. 